\title{
Sociocultural Theory in Practice: The Effect of Teacher, Class, and Peer Scaffolding on the Writing Development of EFL Learners
}

\author{
Majid Amerian \\ Dept. of English Language and Literature, Faculty of Humanities, Arak University \\ Arak 38156-8-8349, PO. Box: 879, Iran \\ E-mail: M-Amerian@araku.ac.ir \\ Moussa Ahmadian \\ Dept. of English Language and Literature, Faculty of Humanities, Arak University \\ Arak 38156-8-8349, PO. Box: 879, Iran \\ E-mail: M-Ahmadian@araku.ac.ir \\ Ehsan Mehri (Corresponding Author) \\ Dept. of English Language and Literature, Faculty of Humanities, Arak University \\ Arak 38156-8-8349, Iran \\ E-mail: Ehsan.mehri.work@gmail.com
}

Received: 10-03-2014

doi:10.7575/aiac.ijalel.v.3n.5p.1
Accepted: 18-04-2014

Published: 01-09-2014

URL: http://dx.doi.org/10.7575/aiac.ijalel.v.3n.5p.1

\begin{abstract}
One of the influential concepts of sociocultural theory in language acquisition research is the zone of proximal development, which is an opportunity for language learners to develop their capacities. It is believed that the learner's language development happens through scaffolding in language learning (Bruner, 1983). This study relies on the scaffolding technique to investigate the effect of three forms of scaffolding process, namely teacher, class, and peer scaffolding $_{2}$ on the writing development of EFL learners. To do this, an intact group sample of 30 participants was selected. The participants were doing their essay writing course in which 19 of them were in one class, assumed as the experimental group in the study, and 11 were in another, assumed as the control group. To maintain possible homogeneity of the participants, an Oxford Placement Test was administered to both groups. The experimental group practiced the techniques of teacher, class, and peer scaffolding in three consecutive sessions respectively, while the control group practiced three individual techniques. After analyzing the mean of the total scores in addition to interrater reliability, the multivariate tests, on the quantitative analysis, showed that the control group outperformed the experimental group. For further understanding of the reasons, on the qualitative analysis, the talks in the experimental group were analyzed. Finally, the findings of both quantitative and qualitative methods of analysis are discussed.
\end{abstract}

Keywords: writing development, teacher scaffolding, class scaffolding, peer scaffolding, sociocultural theory

\section{Background}

"Mind is mediated" (Lantolf, 2000, p. 1). This implies that the relationship human mind has in contact with the world is indirect, and in the process of this contact we rely on tools; one of the most important of which is language. This allows us to change the world and bring the environment under control (Maftoon and Ghafoori, 2009) through language as a culturally constructed tool. According to van Lier (1996), language and human mind have "independent processes" (p. 4), but they interact on so many points of human cognitive development in which "linguistic activity is a means through which human mind is organized" (Lantolf and Appel, 1994, p. 26). Sociocultural theory investigates the social formation of the mind in the society from the developmental psychology perspective. Vygotsky, to whom the sociocultural theory is mostly referred, fundamentally formed his theory on the cognitive development of children. Children develop socially from their early days (Vygotsky, 1986). They actually take part in the interaction with their adult interlocutors verbally or nonverbally to acquire the tool based on which they can express their thought.

Vygotsky maintains that the process of learning happens when individuals participate in a social as well as cultural experience (Raymond, 2000 cited in Van Der Stuyf, 2002). In other words, learning is not an individual activity, but a social interaction that happens in goal directed, meaningful contexts. The interaction the individual has is in the form of dialogue with more capable persons. To understand human mind, we have to look into this process of the dialogue which occurs in sociocultural contexts. 
The immediate educational implication of the sociocultural theory has led it to be a favored one in the field of second language education and research. This is attested to Donato and McCormick (1994, p.453) that "sociocultural theory maintains that social interaction and cultural institutions, such as schools and classrooms, have important roles to play in an individual's cognitive growth and development" (see Hoai Huong, 2003). In the classroom setting, the social activities can take the form of books, textbooks, dialogues, interactions, instruction, and questions. This pedagogical implication of the sociocultural theory is closely consistent with Vygotsky's main area of research where the interaction between a child and other people happens through the dialogue in different discourse forms (Bodrova and Leong, 1998).

One of the mostly implicated notions from the sociocultural theory viewpoint is the concept of the zone of proximal development (ZPD). It is basically a developmental concept in which a social community is constructed and by ways of scaffolding the individual can proceed to the next stages of development. In the words of Vygotsky (1986), learning first takes place on a social (intermental level) before it takes place on an individual (intramental) level. A mostly quoted definition of the ZPD maintains that ZPD is

The distance between the actual development level as determined by independent problem solving and the level of potential development as determined through problem solving under adult guidance or in collaboration with more capable peers (Vygotsky, 1978, p. 86).

This concept is not an abstract notion; rather, it is an opportunity for both the learners and teacher in which understanding of the problem in class is created. Within this conceptualization, the teacher does not transmit the bundles of information and knowledge to the learners. Vygotsky actually assumes human as a conscious individual who has constant interaction with the world around, i.e. the development of the individual cannot be separated from its social and cultural contexts. Now, this sociocultural development provides the ZPD through which others activate their scaffolding process and then via interaction construct the development of the person (Kao, 2010).

When the concept of ZPD is put forth, one needs to mention the fundamental process which happens in the zone. This was not deeply investigated in the works of Vygotsky, rather it was Bruner (1983) who first initiated the notion and investigated its practical implication. He introduced the scaffolding process as a "setting up the situation"(Bruner, 1983, p.60) that helps the person/child to gradually get control of the activity and when he is skilled enough, takes over the total control of the activity. In addition, this conceptualization is nicely in consistence with Vygotsky's words that "what the child is able to do in collaboration today he will be able to do independently tomorrow" (Vygotsky, 1986, p.211).

According to Bruner (1983), the function of scaffolding is not to make the task easier for the learner, but actually it is there to make the completion of the task possible via support. However, the support should be tuned in accordance with the features of theoretical tenets. If we divorce scaffolding from the ZPD, it becomes a form of direct instruction (Donovan and Smolkin, 2002), which impedes the co-construction of knowledge through interaction and dialogue. In the sociocultural realm, it is repetitively mentioned by Vygotsky that it is the dialogue, its process and outcomes that makes scaffolding meaningful. In scaffolding, the more capable person, in pedagogical setting the teacher, or peer, manipulates the current state of knowledge of the person through models, cues, prompts, hints, partial solutions, thinkaloud modeling, and direct instruction (Hartman, 2002) in a variety of contexts to trigger the thinking process and knowledge building of the learner in the process of interaction (Lee, 2004). This interaction in sociocultural theory assumes the active participation of both parties (learner and teacher), in which the more knowledgeable person is not viewed as the depositor of knowledge, nor is the learner assumed as the depository of knowledge (Freire, 1970). The prior knowledge of the learner is developed through the assistance of the teacher. Vygotsky believes that the teacher provides the social environment to direct the student. Vygotsky (1986) maintains the importance of this interaction in the instructional setting in the following words

Instruction is only useful when it moves ahead of development. When it does, it impels or wakens a whole series of functions that are in a stage of maturation lying in the ZPD. This is the major role of instruction in development...instruction would be completely unnecessary if it merely utilized what had already matured in the developmental process, if it were not itself a source of development (p.212).

The importance of instructional scaffolding is asserted by Mercer (1995) where the give and take process initiates knowledge and awareness. The end goal here is that to use scaffolding in order to make the learner become selfregulated and be able to solve the problems independently (Hartman, 2002).

Basically, Sam (unknown) divides the three phases of scaffolding as Modeling, Support, and Fading, in which first the behavior is modeled, then the support is given through the performance of the student, and finally the support is reduced in order to make the learner have self-reliance. van Lier (1996) has a deeper elaboration of the scaffolding procedure and divides the process into six stages: (a) the contextual support in which a safe environment is provided, (b) continuity in which the support for performing the task is maintained, (c) inter-subjectivity in which the interaction and involvement of two minds thinking is realized, (d) flow in which there is not harsh force on communication, (e) contingency in which the scaffolding process depends on the learner's reaction, (f) and, finally, hand over that makes the end point in the process in which the learner can do the task without help.

Wood et al. (1976) provide 5 major ways to scaffold: feeding back, giving of hints, instructing, explaining, and modeling. All the activities and means that the more capable person uses are to make the learner competent enough to 
take hold of the activity independently and be able to do the future task of the same kind on his own (see also Wells, 1999).

One of the mostly used tools for teachers for scaffolding is "question". It is through questions that the teacher guides and gives hint, provides feedback, raises awareness and previous knowledge, and reformulates the learners' thinking (Kim, 2010). It is actually a means of directionality. It is a powerful tool for teachers to guide learners' cognitive development and thinking in ESL courses (Gerstein 1996; Gibbsons, 2003). When questions are asked, there are answers from learners. Other learners, on their own part, take these answers as materials to reflect upon and use them for their own initiation in the process of interaction (ibid).

In the area of second language acquisition, so far as the writing skill is concerned, there have been a number of studies in relation to the sociocultural theory of language learning and development. The idea of talk and dialogue followed by writing is conceived as cognitive tools that mediate internalization and externalize internal psychological activity; tools that "construct and deconstruct and regulate knowledge" (Swain \& Lapkin, 2002, p. 181). Therefore, the researcher can investigate the impact of interaction on writing for a deep analysis of the development and learning of the students.

In her study on the peer dialogue in collaborative writing, Storch (1999) found that the talk between the peers had a positive effect on the grammar of the final writing outcome. Storch compared the writing of the joint group with the individual group and found that the former had a better performance so far as the grammar of their writing was concerned. More specifically, the accuracy of the peer scaffolding group, so far as the tense/aspect choice was concerned, improved from $58 \%$ to $78 \%$, and in morphology from $35 \%$ to $84 \%$. Although the peer scaffolding and the collaborative dialogue improve the grammar of writings, Storch does not state anything of the other components of the writing skill: logical development, vocabulary, etc.

Cotteral and Cohen (2003) conducted a research project in which they used the teacher scaffolding in the process of writing for the freshmen at university to see the effect of teacher's talk and assistance on their writing. They concluded that the teacher scaffolding has a significant effect on the accuracy of their writings.

Rezaie (2012) also conducted research in a university setting in which the mediated learning experiences of teacher versus peer scaffolding modes in L2 writing classes were compared. In her study, the scaffolding behaviors observed in teacher and peers, and a comparison between the two was identified. Though the researcher's aim was to estimate which mode of scaffolding was more effective, she took the effect of the scaffolding on writing for granted. This is the case in which both parties in the class showed scaffolding behavior but the teacher used more scaffolding behavior, thus making more learning opportunity for the learners which in effect resulted in a better performance of the participants in the final writing draft.

Studies related to the area of SCT are mostly concerned with the mechanics of writing (Storch, 1999, Cotteral \& Cohen, 2003). Also, Rezaie's (2012) study focused on the process of writing. One of the areas neglected in the literature is the construction of knowledge in the process of talk within SCT's conceptualization of language development in general and writing development in particular. The present study, thus, aims to shed some light on this point.

\section{The study}

\subsection{Research question and hypothesis}

In the previous section, it was argued that most studies in the field of second language acquisition have focused on the writing accuracy and mechanics of writing. Using the sociocultural theory, the mentioned scholars relied on the outcome of the scaffolding process for better performance of the learners so far as their writing accuracy is concerned. In the present study, the researchers try to rely on the writing skill as a holistic skill, taking into account different components of the writing skill, though it should be noted that the view this study holds is that of developmental. Thus, the following question was raised:

-- Do the socio-cultural techniques of teacher scaffolding, class scaffolding, and peer scaffolding have any significant effect on the writing development of EFL learners?

In order to test out the above question, the researchers put forth the following null hypothesis:

-- The socio-cultural techniques of teacher scaffolding, class scaffolding, and peer scaffolding do not have any significant effect on the writing development of EFL learners.

\subsection{Participants}

The participants of this study were from the juniors of English translation in Arak University, Arak, Iran. The participants were of both sexes, ranging from 19 to 26 in age. They were selected as an intact class, just drawing on the fact that they were all in the same entrance year to the university. Despite the class being intact, the researchers also took a proficiency test to establish their language proficiency. Out of 31 participants, one of them could not attend the second session of the treatment in the experimental group; therefore, he was omitted from the study. In one class, participants, 19 learners, were taken as the experimental group (used for scaffolding techniques); while in the other, 11 learners, were taken as the control group (non-scaffolding techniques). 


\subsection{Instrumentation}

To carry out the study, the following instruments were employed:

2.3.1 An Oxford Placement Test (OPT) was administered to the participants of both classes to establish their level of proficiency. Although the class was intact, the researchers intended to assume the performance of the participants on the writing part of the OPT as their base line in the design of the study or the pretest. The results of the OPT almost showed a homogenous group in both of the classes based on the specification of the OPT ranking skills.

2.3.2 For the control group, there were two essays distributed to the learners to reflect upon in the second session of the study. The two essays were on the same topic as those discussed in the experimental group. Also, an unfinished essay was given to the participants of the control group on the last session of the study.

2.3.3 Three tape recording devices were used in both experimental and control groups to record all the directions, negotiations, and dialogues in class for further reflection and analysis.

2.3.4 A questionnaire was also prepared for both the control and experimental groups by the researchers and the teacher of the class, asking the reflection and idea of the participants both on the techniques and attitude toward the procedure conducted in the study

\subsection{Design}

The design of the study was conducted in 3 consecutive experimental sessions, and 3 consecutive sessions in the control group. The within-group and between-group quantitative analyses were carried out. This is on the first phase of the analysis. But the dominant phase of the analysis was devoted to qualitative analysis in which the dialogue between teacher-students, the whole class, and finally among peers in groups were analyzed and discussed. Therefore, a quantitative-qualitative analysis was considered for the discussion of the results. This is for the deep investigation of the process and outcome of the 3 types of scaffolding used in this study. According to the four strands of genetic research, namely: phylogenesis, sociocultural history, ontogenesis, and microgenesis (Lantolf and Thorne, 2006), the current study chooses the microgenesis approach which takes into account the moment to moment changes in the behavior of the participants in talk through scaffolding mechanism (De Guerrero \& Villamil 2000). Moreover, the current study benefits from qualitative data analysis on the extended discourse that teachers and participants shape in the coconstruction of meaning.

\subsection{Procedure}

The treatment of the study consisted of three sessions in addition to the session preceding them for administering the Oxford Placement Test, the writing section of which was assumed as the base line of the writing ability of the participants. The OPT had three sections, the last of which is writing. After prescribing the test, the scores were calculated, and then the writing samples of the learners were kept aside as the base line of the study. The study was conducted through the course syllabus of their essay writing course. The classes were held by the instructor of the course (as one of the researchers), and another researcher attended as an observer. In the first session of the treatment, in the experimental group, the subject of discussion was "freedom". This session was considered as teacher scaffolding. By teacher scaffolding, it is meant that the teacher intervenes for the process of scaffolding. The instructor started the discussion of "freedom" with the cooperation of the learners. After 45 minutes of discussion, the instructor asked learners to write an essay on freedom in 45 minutes. Following this class, in the control group, the instructor just asked the learners to write about "freedom" without any brainstorming with the instructor or other peers. They had 45 minutes to think, and 45 minutes to write.

In the second session of the treatment, one week later, the instructor attended the experimental group. This time, he first introduced the procedure that they had to talk on "physical punishment", but without the involvement of the teacher. This session was considered what this study assumes as class scaffolding in which the whole class enters into interaction without the intervention of the teacher. They had to run the class by themselves. The teacher insisted that he would not intervene in the process of talk and learners had to initiate the interaction among themselves in the whole class. Again, they had 45 minutes to talk, and another 45 minutes to write. In the control group, on the other hand, the instructor again introduced the procedure of the class in which he distributed 2 essays on "physical punishment" (one agreeing with the action, the other disagreeing with it). Learners had to reflect on the essays and write their own essay. They had 45 minutes for reflection, and 45 minutes for writing.

Finally, in the last session of the study, the instructor randomly grouped the participants of the experimental group. This session was considered as peer scaffolding in the process of whom the interaction and dialogue happened among groups (no more than five peers in each group). The instructor introduced the procedure that they were supposed to talk on "telling lie" in their groups for 45 minutes. Following that, they had another 45 minutes for writing on the topic. In the control group this time, the instructor distributed an unfinished essay on the topic of "telling lie" and asked the learners to think about it for 45 minutes, and then complete the essay in whatever manner they preferred individually. All the sessions in both groups were observed and recorded by the researchers. 


\section{Results}

After the treatment, three raters scored the writing samples according to (Bailey and Brown, 1984 cited in Farhady et. al, 1994) scoring rubric. The agreement between the scores was computed via the $20^{\text {th }}$ version of SPSS and through descriptive statistics and correlation coefficient. Table 1 shows the results of the descriptive statistics of the raters' scores given to the participants in the control and experimental groups.

Table 1. Descriptive Statistics of the Rater's Scores in Writings 1, 2, 3, \& 4

\begin{tabular}{lcccccc}
\hline & Rater 1 & \multicolumn{2}{c}{ Rater 2 } & \multicolumn{2}{c}{ Rater 3 } \\
\cline { 2 - 7 } & $M$ & $S D$ & $M$ & $S D$ & $M$ & $S D$ \\
\hline Writing 1 & 79.43 & 8.90 & 78.53 & 7.28 & 74.26 & 8.79 \\
\hline Writing 2 & 77.78 & 6.78 & 82.64 & 6.93 & 89.00 & 7.22 \\
\hline Writing 3 & 82.17 & 7.40 & 81.62 & 7.87 & 70.96 & 9.43 \\
\hline Writing 4 & 81.75 & 6.78 & 77.00 & 9.26 & 70.03 & 11.37 \\
\hline
\end{tabular}

According to this table, the raters' mean scores in Writing 1 are convergent, that is $M=79.43$ for Rater $1, M=78.53$ for Rater 2, and $M=74.26$ for Rater 3. The same pattern is followed in Writing 2 results, in which $M=77.78$ for Rater 1 , $M=82.64$ for Rater 2, and $M=89.00$ for Rater 3. This consistency is maintained in the Writing 3 results, so that $M=82.17$ for Rater $1, M=81.62$ for Rater 2, and $M=70.96$ for Rater 3. Finally, in Writing $4, M=81.75$ for Rater $1, M=77.00$ for Rater 2, and $M=70.03$ for Rater 3. To further investigate the agreement between these scores, Pearson product-moment correlation coefficient was computed (see Table 2). As shown in this table, there was a strong relationship between the raters, since all the values are above the alpha level $(\mathrm{r}=.01)$. Thus, the scores had high inter-rater agreement.

Table 2. Pearson Coefficient Correlation of the Rater's Scores in Writings 1, 2, 3, \& 4

\begin{tabular}{|c|c|c|c|c|}
\hline \multicolumn{2}{|c|}{ Writing } & \multirow{2}{*}{ Rater1 } & \multirow{2}{*}{$\frac{\text { Rater2 }}{.613 * *}$} & \multirow{2}{*}{$\begin{array}{l}\text { Rater3 } \\
.559 * *\end{array}$} \\
\hline & Rater1 & & & \\
\hline \multirow[t]{3}{*}{1.00} & Rater2 & $.613^{* *}$ & - & $.748 * *$ \\
\hline & Rater3 & $.559 * *$ & $.748 * *$ & - \\
\hline & Rater1 & - & .568 & .582 \\
\hline \multirow[t]{3}{*}{2.00} & Rater2 & $.568 * *$ & - & $.667 * *$ \\
\hline & Rater3 & $.582 * *$ & $.667 * *$ & - \\
\hline & Rater1 & - & $.605 * *$ & $.752 * *$ \\
\hline \multirow[t]{3}{*}{3.00} & Rater2 & $.605^{* *}$ & - & $.739 * *$ \\
\hline & Rater3 & $.752 * *$ & $.739 * *$ & - \\
\hline & Rater1 & - & $.501 * *$ & $.542 * *$ \\
\hline \multirow[t]{2}{*}{4.00} & Rater2 & $.501 * *$ & - & $.666^{* *}$ \\
\hline & Rater3 & $.542 * *$ & $.666^{* *}$ & - \\
\hline
\end{tabular}

**. Correlation is significant at the 0.01 level (2-tailed).

The high inter-rater agreement led the researchers to use the average of scores as the main score for each participant. For analyzing the scores of the participants in four writings, a one-way between-groups multivariate analysis of variance was performed. Three independent variables were used: teacher scaffolding, class scaffolding, and peer scaffolding. The dependent variable was writing. The Preliminary assumption testing was conducted to check for normality, linearity, univariate and multivariate outliners, homogeneity of variance-covariance matrices, and multicollinearity, with no serious violations noted.

The results of the multivariate tests in Table 3 show that there was a statistically significant difference between the experimental and the control groups on the combined dependent variables, $F(4,18)=4.53, p=.010$; Pillai's trace $=$ .50 ; partial eta squared $=.50$. 
Table 3. Multivariate Tests

\begin{tabular}{llrrrrrr}
\hline $\begin{array}{l}\text { Effect } \\
\text { Squared }\end{array}$ & & Value & F & Hypothesis df & Error df & Sig. & Partial Eta \\
\hline \multirow{6}{*}{ Intercept } & Pillai's Trace & .886 & $34.950^{\mathrm{b}}$ & 4.000 & 18.000 & .000 & .886 \\
& Wilks' Lambda & .114 & $34.950^{\mathrm{b}}$ & 4.000 & 18.000 & .000 & .886 \\
& Hotelling's Trace & 7.767 & $34.950^{\mathrm{b}}$ & 4.000 & 18.000 & .000 & .886 \\
& Roy's Largest Root & 7.767 & $34.950^{\mathrm{b}}$ & 4.000 & 18.000 & .000 & .886 \\
& Pillai's Trace & .502 & $4.539^{\mathrm{b}}$ & 4.000 & 18.000 & .010 & .502 \\
& Wilks' Lambda & .498 & $4.539^{\mathrm{b}}$ & 4.000 & 18.000 & .010 & .502 \\
group & Hotelling's Trace & 1.009 & $4.539^{\mathrm{b}}$ & 4.000 & 18.000 & .010 & .502 \\
& Roy's Largest Root & 1.009 & $4.539^{\mathrm{b}}$ & 4.000 & 18.000 & .010 & .502 \\
\hline
\end{tabular}

When the results for the dependent variables were considered separately, the only difference to reach statistical significance, using a Bonferroni adjustment alpha level of .006, was Writing 3, $F(1,21)=11.12, p=.003$, partial eta squared $=.34$. An inspection of mean scores indicated that the individual group had a better performance on Writing 3 $(M=82.60, S D=7.14)$ than the social group $(M=76.51, S D=4.06)$. These results are also illustrated in Figure 1 .

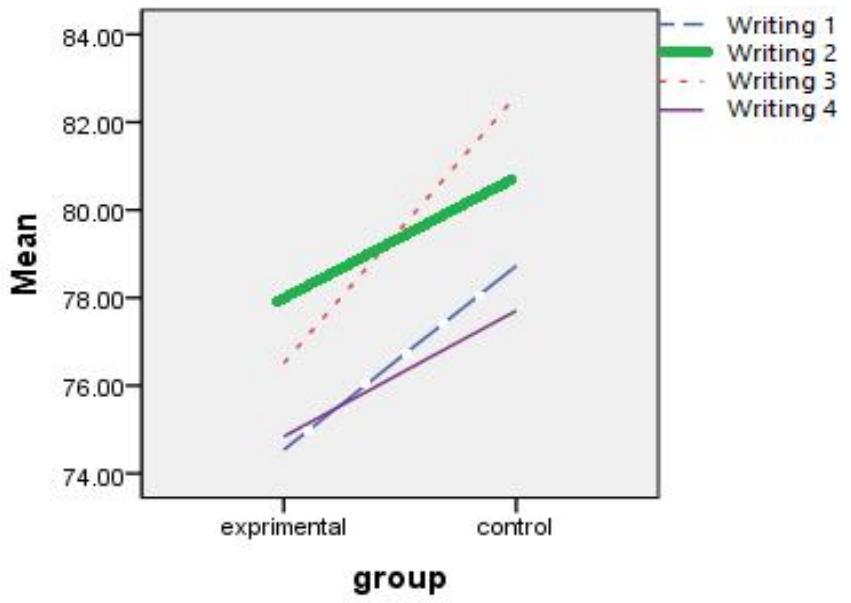

Figure 1. The Mean Scores of the Participants in Writings 1, 2, 3, \& 4

Although the analysis of the results showed a significance difference between the groups' performance only in Writing 3 , the pattern of participants' writing performance was investigated through descriptive statistics to find differences between the two groups. The participants had a close performance on Writing 1. For the experimental group $M=74.53$, $S D=5.36$, and for the control group $M=78.73, S D=6.01$. Also, the control group obtained a higher mean score $(M=80.76, S D=5.41)$ than the experimental group $(M=77.98, S D=4.43)$ in Writing 2 . This difference in Writing 3 is for the control group $(M=82.60, S D=7.14)$ and the experimental group $(M=76.51, S D=4.06)$. The same pattern of difference was observed for Writing 4, though the mean scores of the groups are closer as it was in Writing 1 . For the experimental group, $M=74.83, S D=5.85$, and for the control group, $M=77.70, S D=7.30$.

An overall observation of the mentioned patterns of performance on the four writings indicated that the highest performance of the two groups belonged to Writing 2(teacher scaffolding), followed by Writing 3(class scaffolding), and the lowest total mean scores belonged to Writing 4 (peer scaffolding).

In the second phase of data analysis, we will refer to the dialogues and interaction in process in the three experimental sessions to see any possible justification. As was previously mentioned, the students had a better performance, so far as their scores were concerned, in the teacher scaffolding session, though they did not outperform the control group. Here the researchers intended to exemplify the scaffolding modes used in the three techniques of scaffolding. For the most part, the teacher scaffolding session was abounded with questions, compared with the other two sessions of class scaffolding and peer scaffolding. Also, another characteristic of the teacher scaffolding was the reformulation and explanation the teacher provided following the students' answers to the questions. On the average, the teacher tried to have one reformulation and elaboration of ideas in every 4 exchanges. Therefore, the number of elaboration and explanation was significant in comparison with other sessions of the study. The following table illustrates the point more clearly. 
Table 4. Scaffolding techniques and the frequency of their realization

\begin{tabular}{l|cccc}
\hline \multicolumn{1}{c}{ realizations } & I think... & Questions & Silence & Reformulation \\
Techniques & & & & \\
\hline Teacher scaffolding & 9 by students & 74 by teacher & $2-4$ seconds & 20 by teacher \\
\hline Class scaffolding & 25 & 13 & $5-16$ seconds & --- \\
\hline Peer scaffolding Group 1 & 17 & 9 & $4-5$ seconds & --- \\
\hline Peer scaffolding Group 2 & 10 & 13 & $4-7$ seconds & --- \\
\hline Peer scaffolding Group 3 & 12 & 3 & ---- & --- \\
\hline
\end{tabular}

One of the most salient features of teacher scaffolding is reformulation. By reformulation, it is meant the process of teacher's taking learner's limited ideas, then expanding them with some comment, and finally representing the reconstructed idea to the learners. In this study, the teacher used reformulation 20 times in the zone of proximal development. The number of questions that the teacher asked in the teacher scaffolding session in comparison with other sessions in which the dialogue was in process is significant, as Table 4 shows. This is in line with Cazden (1988) who maintains that "question" is the mostly used technique of teachers in the process of scaffolding. An example might make the point clearer:

Teacher: of course you may not announce that and nobody knows that you have changed your religion but the question is this. When you say humanity, human right, what do we mean? Sometimes we say something but it seems we don't know what we say.

Student: for example, to see the Palestine, Palestinian people are just human being, but they are living on a lots of prejudice, so we just, we look at America at this point. And we say how it is (unclear)

Teacher: I don't know what you are talking about, you know, you talk about Palestinian people and United States, that is not our point of discussion today. We like to see, we like to see what freedom is.

In this extract from the first session, the teacher first comments on what the student previously mentioned on one aspect of "freedom", here humanity. He makes what the students said coherent and to the point. But again, he raises the question of what he means exactly by humanity in discussing "freedom". In reaction, the student provides an example. This exemplification mostly happens when the learner cannot convey what he exactly means. Also, this characteristic is observed in peer scaffolding in which each person's ground is closer to that of his peer since the community in which the dialogue happens is smaller. But in this extract, the teacher reacts to the example of the learner through giving feedback that he cannot make sense of the student's example. It seems that the two means of questioning and reformulation have a more significant result on the writing development of the learners. This is because learners' average score outperformed that of learners in the other 2 sessions of the experimental group. In statistical terms, teacher scaffolding had the average score of 77.98, while the other two sessions had the average scores of 76.51 and 74.83 respectively (see Figure 1). In addition, as Table 4 illustrates, the silence between interactions, which is 2 to 4 seconds, contributes to more interaction, on the one side, and more scaffolding opportunity on the other, to help the learners realize the brainstorming phase of writing.

There were some questions in other sessions of the study but the learners tended to have opinion exchanges, and explanation within their own interactions. In the class scaffolding session, in which all the participants were engaged, without the assistance and intervention of the teacher, learners mostly relied on "I think" utterances, and tried to give their opinions through explanation to persuade each other of what they thought was right. Of course, one point should be mentioned. In the class scaffolding session, one student had a thoroughly different opinion regarding the topic of discussion "physical punishment". She was in agreement with the act of physical punishment, though other classmates were in disfavor of this behavior. They all tried to scaffold through explanation and reasoning; this is in line with Wood et al.'s (1976) 5 major ways to scaffold: feeding back, giving hints, instructing, explaining, and modeling. The students, mostly, tried to explain, model, and put forth their ideas in the process of persuading the one peer who was in disagreement with the others. Furthermore, they used the means of questioning, but it is not significant in comparison with teacher's use of this device. Although they followed Wood et al.'s (ibid) category, the learners were not cooperative in the process of negotiation, each avoiding a joint construction of knowledge.

What is significant here is the "I think" utterance. The learners tried to protect their own ground on the assumption that this would make the disagreed student change her perspective. In the following extract, the point is illustrated:

S1: but I think it depends on the children. Some children are very, I don't know, bad tempered and you should punish them from the first day. We can't have children if they are not punished physical.

S2: I think physical punishment, just makes children more sensitive to, to, $\mathrm{mm}$, to do the bad things that we wants to stop them and I think it's not a suitable way to stop children from...

S1: physical punishment is not a good way, but sometimes it's not a way better than physical punishment (unclear) 
S3: but in all situation, it's not helpful for all children. Maybe physical punishment may children show a aggressive behavior.

S1: but it's a definite absolution for treating children especially for some bad tempered children

S4: I think...

In this extract, taken from the class scaffolding session, $\mathrm{S} 1$ agrees with physical punishment as an appropriate method for ill-mannered children. She explains what this action is good for. On the other hand, students 2, 3, and 4 have the opposite idea and begin an interaction with S1. They are trying to protect their ground. All of the learners in this extract are explaining their ideas and providing a reason for their opinions. In Vedder's (1985) classification of peripheral factors affecting scaffolding, learners have to make relevant their explanation to other learners, try to clear any misunderstanding, and use the opportunity for explanation to solve the problem. They are following the first and the third criteria mentioned here. But they are not taking note of what basis S1 is making her claim. She repeatedly mentions that "sometimes" physical punishment is an appropriate way for ill-mannered learners, but other learners mostly try to convince her that it is totally wrong to punish children. It might be claimed that their explanation is not relevant to S1's explanation, though on the surface they are making their point in opposition to what S1 is putting forth. This is one of the basic reasons that the "I think" utterances are more in comparison with teacher scaffolding and peer scaffolding sessions.

Another significant point in this session was the silent period. In other sessions, the learners were in disagreement with minor details of their topic of discussion, while in the second session there were differences among learners, on the subject of "physical punishment", in which S1 agrees for most of the time. Learners tried to reflect on finding a way to persuade the only participant whose idea was not in line with the others. Therefore, in this session, the silent period took between 5 to 16 seconds, which is significant in an interaction. One reason also for declining in their writing in this session might be that learners have not been able to open their ground on each other, specifically with S1 to do scaffolding. They are using the scaffolding ways and means but it is not purposeful to fulfill the desired outcome. Mostly they insist on their ground again in their writing and have not taken advantage of the opportunity to talk for developing their writing skill.

In the third, and last, session of the study, learners used the device of questioning, opinion exchange, and explanation for scaffolding for a few times (for the sake of space, we did not provide an example here). Although their silent period was less than 2 seconds, they had not good performance in their writing. But there seems to be a significant aspect to peer scaffolding. In this session, learners tried to open their ground for discussion and elaboration. They used more examples of their personal life. Of course, it might be because of the topic of the discussion i.e. "telling lies", but at the same time the length of the moves in each exchange was longer than other lengths of talk in the 2 preceding sessions. Of course, long length of moves might be related to the talk students are engaged in, since the teacher, in his reformulation and expansion of the ideas had the most length of the talk, but students had more to say in their groups in comparison with the other sessions. Although they had more opportunity for interaction, the effect of this was not reflected in their writing, as an externalized realization. Their low average score (see Figure 1) might be because of the exemplification of the students, since in their talk, it was observed that they mostly tried to provide examples. This input might not be suitable for the learner as an internalized material for being externalized in the writing phase of the study. Another reason for the low average score could be the rare contribution they had in their discussion. Their talk sometimes diverged into peripheral talk, jumping from one branch to another specifically when they talked about their experience in telling lies. This might cause their being not on the track. It should be mentioned that the teacher was not involved in any of the groups' interaction; therefore, learners were on their own to proceed in their dialogue.

\section{Discussion}

In this article, three forms of scaffolding were investigated. The OPT writing was assumed to be the base line of the learners' writing proficiency. The results revealed that the teacher scaffolding had a positive effect on the writing development of the learners as a whole, in contrast with other studies (Byrd, 2003; Kepner, 1991; Lalande, 1982; Paton, 2002, De Guerrero and Villamil, 2000) which focused on the mechanics of writing. Then, the features of class scaffolding, and peer scaffolding, as defined in previous sections, did not have a significant effect on the writing development of the learners, though in between-group comparison, the experimental group did not outperform the control group.

Referring to the first session of the study in the experimental group, the teacher tried to establish an environment for socialization, which is to make the flow of mutual exchange current. Providing a safe environment was established with giving enough waiting time for learners to reflect upon so many questions he asked. At first, learners might think that they could not answer the questions (Webb, 1989), but the reformulation and expansion of ideas from the teacher's side let them engage in the process of interaction. Palincsar (1986) also believes that in the process of talk between student and teacher, the teacher uses available means including questions, discussion, elaboration, and summarization to make the learner not only to reflect on what is said, but also to initiate an attempt for the output. The mostly used device in our study was that of questioning. The teacher initiated the talk followed by a question, to which the learners responded, and the teacher gave feedback, elaborated the response, and then raised another question in line with the previous talk. That is, he actually used the IRF pattern of dialogue at the same time making a connection with the learners' background knowledge (Allahyar and Nazari, 2012). 
In the flow of the talk, some learners avoided initiating talk, and some also totally tried to avoid their talk at the beginning. McDonough (2004) cites Davis's (1997) and Fotos's (1994) study in which they maintain that learners, in interaction with their teacher, might feel that they are not good sources for the dialogue, and rely on their teacher for the most parts. Now, in the context of Iranian EFL, the accustomed way of instruction in academic classes is in the form of the monologue. Also, in the academic setting, the learners might assume that if they talk they might seem incompetent in the interaction with the teacher and their peers, so they might try to work on their own (Nelson-Legal, 1981). This might have effects on the process of talk, since learners did not talk a lot, but the teacher raised so many questions and used those few utterances from learners to expand the negotiation.

In the control group, learners did better than those learners in the teacher scaffolding session, and outperformed in all the sessions in between-group comparison with the experimental group. They worked individually without any assistance. On the other hand, participants in the experimental group, where they received teacher scaffolding technique, showed increase in their writing performance. Webb (1989) believes that there are students who might not seem willing to ask questions or risk making errors but they possibly still learn from the interaction among group members. All in all, the number of scaffoldings that happened in the teacher scaffolding session was way more than other sessions, 74 questions and 20 reformulations, though this was not enough to outperform the control group. The scaffolding should be repeated enough to let the learner develop. Donovan and Smolkin (2002) assert that the right amount of scaffolding has effect on the outcome of the interaction. Webb (1989) also maintains that if the number of scaffolding, both from teacher and peers, is not enough, it cannot contribute the learners in the activity.

In the second and the third sessions of the study, the teacher did not intervene in the process of scaffolding and interaction. In the second session, as mentioned before, the whole class was let initiate talk, take the control of the class, and move on in their process of dialogue by themselves. Of significant features of class scaffolding was the position one learner took regarding the topic of "physical punishment" in that she agreed with punishing children physically. This opened up a full account of scaffolding from all sides of the class. In teacher scaffolding, it was observed that the number of times for scaffolding to be effective should be high enough to have an effect on their writing realization. Now, in class scaffolding, the learners did not open their group. This happened in a situation that only one learner was in disagreement with other peers. Hartup (2005) maintains that "sometimes group activities can be aimed at positive, prosocial outcomes but actually result in increased antisocial activity; this is especially likely when intervention groups consist of an aggregate of antisocial peers" (p. 388). Although in this study the researchers do not judge the idea of the learner having opposing ideas, Hartup (ibid) conceptualizes this as swimming against the flow of interaction. The learner's idea was considered as "antisocial" to the community of practice in class scaffolding session. All the interaction was pointed toward her, and the learners tried whatever they could to persuade her conform to the majority's idea, namely through devices of explanation, hint, example, and modeling (Wood et al, 1976).

Actually, unlike teacher scaffolding in which the teacher and learners passed the three phases, introduced by Clark and Graves (2005), in the class scaffolding and also in the peer scaffolding session, the learners could not move over the joint responsibility phase of scaffolding procedure. The defensive environment that was observed in the class scaffolding and to some extent in the peer scaffolding session could have two sources. First, it could be related to the features of class scaffolding that friends and non-friends were having the dialogue. Second, it could be related to the random selection of groups in the peer scaffolding session that disregarded the social and psychological match between learners. Hartup (2005) argues that those learners who have more intimate relationship can handle the task more effectively in comparison with those who are known to be non-friends. This is the case while Swain et al. (2002) mention that it is not the matter of being expert or more proficient that could assist the scaffolding procedure. But as in the case of class scaffolding and peer scaffolding, it was observed that in most dialogues learners tried to prove that they were right in their opinion. In other words, learners, in opportunity of interaction in which they have to give and take their opinions and ideas, tried to take the role of dominant and controlling behavior, and most often rejected others' ideas (Storch, 2000).

According to Wood et al. (1976), for scaffolding to be effective, learners have to: a) recruit the tutee's attention, (b) reduce degrees of freedom in the task in order to make it manageable, (c) keep direction in terms of the goals, (d) mark critical features, (e) control frustration, and (f) model solutions, while in the observed behavior of the learners they could only recruit the tutee's attention. This is different from the teacher scaffolding session in which the teacher through the devices of elaboration, explanation, and questions tried to keep learners' attention, direct them, model solution, make understanding of the talk critical, and give a model for the solution by pointing to some notes and providing comments on learners' output. In the class scaffolding and peer scaffolding sessions that the environment tended to be guided by tension, the learners used examples in their "I think" utterances. The point here is that learners may not know exactly how to proceed in the process of scaffolding. The teacher, who was well familiar with SCT and its pedagogical implications, could benefit from the scaffolding techniques and means appropriately, but this does not mean that students can take such a role. Learners need to be taught how to scaffold. In the Iranian educational system in which the dominant mode of teaching is teacher centered through the monologue, the scaffolding techniques of social constructivism approach might not be effective when learners take the control. Maftoon and Nasser (2009) maintain that learners need time and practice for scaffolding. They have to be taught explicitly how and when to scaffold.

Now, it is time to discuss some points regarding the better performance of the control group in which they could have similar and even higher, scores in their writings. Although in the control group learners had no interaction with others, the instructor of the course asserted that he felt the control group was more capable than the experimental group in their 
interactional behavior. On the other hand, writing is an individual work. Learners upon reflecting on their writings, which was the basic feature of all the three sessions in the control group, could play with their own ideas. They could explain, elaborate, and expand what they thought was appropriate without being affected or distracted by an outside idea. This is especially important when a peer can intimidate, frustrate, and destroy their safe personal environment. They had enough time to think about what they wanted to write, while in the experimental group in their 45 minutes, they were let have the dialogue with others, and the second 45 minutes were considered for writing their essay. Although there is a statistical difference between the control (individual) and the experimental (social) group, the difference is not significant. It was mentioned earlier that the control group outperformed the experimental group, but so far as statistics shows, the evidence is not providing a firm support for the claim.

It is interesting that both groups of this study had similar lines of increase and decrease. In the control group, similar to the experimental group, the first session as well as the second session was positively effective, and the third sessions were negatively effective. This could mean that the difficulty of the topics introduced to the learners was not to be considered as a separate variable in their writing outcome. Unlike Van Der Stuyf (2002) who maintains that in the absence of social interaction, learning and development could be hindered, this study could provide evidence that the use of social techniques of SCT sometimes tend to be culture specific, especially in societies where they are brought up within a monologue-based educational system. It was argued above that the dominant pedagogical behavior in the educational system of Iran tends to be teacher centered and monological. Therefore, one cannot guarantee the success of SCT techniques. As mentioned above, there was not a significant difference between the control and experimental groups, but since the environment of the education in the research setting is that of the monologue, there needs to be more time for the reception and establishment of the social techniques, here scaffolding. One might argue that the learners can do well with individual techniques in the monologue based educational system, but the construction of knowledge claimed by SCT has a long term effect on the cognitive development of learners. Therefore, the experimental (social) techniques might need more time for better performance in their writing development.

\section{Conclusion}

This study aimed at investigating the effect of three modes of scaffolding, namely teacher, class, and peer scaffolding on the writing development of learners. The learners in the experimental group who benefited from scaffolding techniques did not outperform the control group who did their task individually. Confirming this on the quantitative plane, the qualitative analysis revealed that the increase in the average score of teacher scaffolding session was due to the teacher's being in line with the procedures of scaffolding and his familiarity with the realization of the scaffolding concept. Learners need to be taught on how to scaffold (Nassaji and Tian, 2010). The process of scaffolding and productive dialogue is not a mere chance and guaranteed process, especially in societies where individuals are not familiar enough to have group work and interactional relationship. In addition, learners have to be encouraged to set a safe environment within their dialogue to accept the flow of negotiation on their immediate task. Building a wall around themselves, learners in this study did not let themselves and other's enter the zone of proximal development; therefore, they need to realize that the dialogue is a mutual respective negotiation of ideas, that no one is right all the time, and that interaction is to bear into the construction of knowledge, not merely confirming one's own idea. Also, researchers have to be careful about the implication of scaffolding where learners rely on their teachers in the construction of knowledge and their own development. Consequently, group work and peer interaction will not necessarily lead to development.

\section{References}

Allahyar, N., and Nazari, A. (2012). Potentiality of Vygotsky's sociocultural theory in exploring the role of teacher perceptions, expectations and interaction strategies. WoPaLP, 6, 79-92.

Bodrova, E. and Leong, D. J. (1998). Scaffolding emergent writing in the zone of proximal development. Literacy teaching and learning, 3(2), 1-18.

Bruner, J. (1983). Child's talk. New York: Norton.

Byrd, D. (2003). Practical tips for implementing peer editing tasks in the foreign language classroom. Foreign Language Annals, 36(3), 434-441.

Cazden, C. B. (1988). Classroom discourse: The language of teaching and learning. Portsmouth, NH: Heinemann.

Clark, K. F., and Graves, M. F. (2005). Scaffolding students' comprehension of text. Reading Teachers, 58(6), 570-580.

Cotteral, S., and Cohen, R. (2003). Scaffolding for second language writers: producing an academic essay. EFL Journal, 57(2), 158-166.

De Guerrero, M. C. M. and Villamil, O. (2000). Activating the ZPD: mutual scaffolding in L2 peer revision. The Modern Language Journal, 84(1), 51-68.

Donato, R. and McCormick, D. (1994). A sociocultural perspective on language learning strategies: the role of mediation. The Modern Language Journal, 78(4), 453-464.

Donovan, C. and Smolkin, L. (2002). Children's genre knowledge: an examination of K-5 students performance on multiple tasks providing differing levels of scaffolding. Reading Research Quarterly Newark, 37(4), 428-465.

Farhady, H., Ja'farpur, A. and Pirjandi, P. (1994). Testing language skills: from theory to practice. Iran: SAMT. 
Freire, P. (1970). Pedagogy of the oppressed. New York: Seabury Press.

Gerstein, R. (1996). Literacy instruction for language-minority students: the transition years. The Elementary School Journal, 96(3), 237-244.

Gibbons, P. (2003). Mediating language learning: teacher interaction with ESL students in a content-based classroom. TESOL Quarterly, 37(2), 247-273.

Hartman, H. (2002). Scaffolding and cooperative learning. Human Learning and Instruction, (pp. 23-69). New York: City College of City University of New York.

Hartup, W. W. (2005). Peer interaction: what causes what?.Journal of Abnormal Child Psychology, 33(3), $387-394$.

HoaiHuong, L. P. (2003). The meditational role of language teachers in sociocultural theory. English Teaching Forum, 41(3), 31-35.

Kao, P. (2010). Examining second language learning: taking a sociocultural stance. ARECLS, 7, 113-131.

Kepner, C. (1991). An experiment in the relationship of types of written feedback to the development of second language writing skills. The Modern Language Journal, 75, 305-313.

Kim, Y. (2010). Scaffolding through questions in upper elementary ELL learning. Literacy teaching and learning, 15(12), 109- 137.

Lalande, J. (1982). Reducing composition erros: an experiment. The Modern Language Journal, 66(2), 140-149.

Lantolf, J.P. (2000). Sociocultural theory and second language learning. China: Oxford University Press.

Lantolf, J. P. and Appel, G. (1994). Theoretical framework: an introduction to Vygotskian perspectives on second language research. In J. Lantolf and G. Appel (ed.), Vygotskian approaches to second language research(pp 1-31). Westport, CA: Albex Publishing.

Lantolf J. P. and Thorne S. L. (2006). Sociocultural theory and the genesis of second language development. Oxford: OUP.

Lee, H.L.(2004) cited in Ministry of Education, Singapore. (2005) Information booklet on Education. Retrieved from http://www.moe.gov.sg/corporate/overview_01.htm

Maftoon, P. and Nasser, Gh. (2009). A comparative study of the effect of homogeneous and heterogeneous collaborative interaction on the development of EFL learners' writing skill. The Journal of Applied Linguistic, 2(1), 127-158.

McDonough, K. (2004). Learner-learner interaction during pair and small group activities in a Thai EFL context. System 32(2), 207-224.

Mercer, N. (1995). The guided construction of knowledge. Clevedon, England: Multilingual Matters.

Nassaji, H. and Tian, J. (2010). Collaborative and individual output tasks and their effect on learning English phrasal verb. Language Teaching Research, 14(4), 397-419.

Nelson-Legal, S. (1981). Help-seeking: an understudied problem solving skill in children. Developmental Review,1(3), 224-246.

Palincsar, A. S. (1986). The role of dialogue in providing scaffolded instruction. Educational Psychologist, 21(1-2), 7398.

Paton, F. (2002). Approaches to productinve peer review. In D. Roen, Pantoja, V. Yena, L., Miller, S., and Waggoner, E., (Eds.), Strategies for teaching first year composition (pp. 290-300). Urbana: NCTE.

Rezaei, M. (2012). Mediated learning experience: Teacher vs. peer scaffolding modes in L2 writing classes. The Iranian EFL Journal, 8(1), 71-96.

Sam, C. (unkonwn). Purposeful scaffolding: beyond modeling and thinking aloud. Retrieved from conference.nie.edu.sg/paper/Converted\%20Pdf/ab00655.pdf

Storch, N. (1999). Are two heads better than one? Pair work and grammatical accuracy. System, 27(3), 363-374.

Storch, N. (2000). Is pair work conducive to language learning? The nature of assistance in adult ESL pair work and its effect on language development. Paper presented at the conference on Scaffolding and Language Learning in Educational Contexts: Socio-cultural approaches to Theory and Practice. Centre for Language and Literacy, University of Technology, Sydney.

Swain, M., Brooks, L. and TocalliBeller, A. (2002). Peer peer dialogue as a means of second language learning. Annual Review of Applied Linguistics,22(1), 171-185.

Swain, M., and Lapkin, S. (2002). Talking it through: Two French immersion learners' response to reformulation. International Journal of Educational Research, 37(3-4), 285-303.

Van Der Stuyf, R. R. (2002). Scaffolding as a teaching strategy. Retrievedfrom condor.admin.ccny.cuny.edu/.../Van\%20Der\%20Stuyf\%20Paper.doc

Van Lier, L. (1996). Interaction in the language classroom. Essex: Longman Group. 
IJALEL 3(5):1-12, 2014

Vedder, P. (1985). Cooperative learning : a study on processes and effects of cooperation between primary school children. Westerhaven Groningen. Netherlands: Rijkuniversiteit Groningen.

Vygotsky, L. (1986). Language and thought. USA: MIT. (English translation)

Vygotsky, L. (1978). Mind in society: The development of higher psychological processes. Cambridge: Harvard University Press. (English translation)

Webb, N. M. (1989). Peer interaction and learning in small groups. International Journal of Educational Research, $13(1), 21-40$.

Wells, G. (1999). Dialogic inquiry: toward a sociocultural practice and theory of education. Cambridge: Cambridge University Press

Wood, D., Bruner, J. S., and Ross, G. (1976). The role of tutoring in problem solving. Journal of Child Psychology and Psychiatry and Allied Disciplines, 17(2),69-100. 